\title{
Effects of Cyclic Strain and Growth Factors on Vascular Smooth Muscle Cell Responses
}

\author{
Soujanya Kona ${ }^{\dagger, 1}$, Prithiviraj Chellamuthu ${ }^{\dagger, 2}$, Hao Xu ${ }^{1}$, Seth R. Hills ${ }^{2}$ and Kytai Truong Nguyen ${ }^{*, 1,2}$ \\ ${ }^{I}$ Department of Bioengineering, University of Texas at Arlington and University of Texas Southwestern Medical Center \\ at Dallas, USA \\ ${ }^{2}$ Department of Biological and Irrigation Engineering, Utah State University, USA
}

\begin{abstract}
Under physiological and pathological conditions, vascular smooth muscle cells (SMC) are exposed to different biochemical factors and biomechanical forces. Previous studies pertaining to SMC responses have not investigated the effects of both factors on SMCs. Thus, in our research we investigated the combined effects of growth factors like bFGF (basic fibroblast growth factor), TGF- $\beta$ (transforming growth factor $\beta$ ) and PDGF (platelet-derived growth factor) along with physiological cyclic strain on SMC responses. Physiological cyclic strain (10\% strain) significantly reduced SMC proliferation compared to static controls while addition of growth factors bFGF, TGF- $\beta$ or PDGF-AB had a positive influence on SMC growth compared to strain alone. Microarray analysis of SMCs exposed to these growth factors and cyclic strain showed that several bioactive genes (vascular endothelial growth factor, epidermal growth factor receptor, etc.) were altered upon exposure. Further work involving biochemical and pathological cyclic strain stimulation will help us better understand the role of cyclic strain and growth factors in vascular functions and development of vascular disorders.
\end{abstract}

Keywords: Cyclic Strain, Growth Factors, Proliferation, Gene Regulation, Vascular Smooth Muscle Cells.

\section{INTRODUCTION}

Recent studies have demonstrated that biomechanical factors like cyclic strain and shear stress play a major role in normal vascular function and early development of vascular diseases [1-4]. Particularly, previous efforts investigating effects of cyclic strain on SMC functions found that cyclic strain could regulate both normal cellular functions and pathophysiological changes. For instance, pathological cyclic strain (>15\%) increases DNA synthesis by increasing reactive oxygen species (ROS) production and activation of NF-kB in cultured SMCs [5] while physiological levels of cyclic strain (10\% strain) inhibit SMC growth by increasing cyclin-dependent kinase inhibitor p21 and promoting apoptosis [6,7]. One study suggests that "physiological stretch" maintains SMCs in quiescent state and "pathological stretch" initiates SMC proliferation [8]. These studies indicate that physiological cyclic strain contributes to vascular homeostasis by inhibiting cell cycle and enhancing apoptosis, while overstretching leads to intimal thickening by stimulating SMC growth.

In addition to cyclic strain, biochemical factors such as growth factors also play an important role in SMC responses, and the SMC response to growth factors is also well-studied. For instance, studies have shown bFGF to be an important mitogen while PDGF acts as a chemotactic agent in SMC proliferation [9-11]. Research has also shown TGF- $\beta$ to be a

\footnotetext{
*Address correspondence to this author at the Department of Bioengineering, University of Texas at Arlington, 501 West First Street, ELB 220, Arlington, TX 76019, USA; Tel: 817-272-2540; Fax: 817-272-2251; E-mail: knguyen@uta.edu

${ }^{\dagger}$ Both Authors Contributed Equally.
}

potent antiproliferative and proliferative molecule for SMCs depending on its concentration $[12,13]$. Of all these growth factors, it is well known that PDGF can enhance the SMC growth under static conditions $[14,15]$. In addition, studies have shown that SMC growth is altered at different levels by cyclic strain and is determined by the amplitude and frequency of strain, by stimulating the expression and production of various growth factors, such as fibroblast growth factor-2 (FGF-2) [11, 16], PDGF [17], and insulinlike growth factor 1 (IGF-1) [18]. Furthermore, growth factor receptors such as epidermal growth factor receptor (EGFR) and protease activated receptor-1 (PAR-1) are also activated by cyclic strain $[19,20]$, leading to the induction of cell proliferation.

This research aims to investigate SMC responses to cyclic strain in the presence of growth factors (bFGF, TGF- $\beta$ or PDGF-AB). bFGF and TGF- $\beta$ were selected as the biochemical stimulants as an increased amount of these growth factors has been found in regions of atherosclerotic plaques [21-28]. Studies have also shown that an increased amount of PDGF is seen at sites of atherosclerotic plaques $[14,29]$. Pilot studies were conducted to determine the optimal concentrations of each growth factor for enhanced cell proliferation and were used later in our experiments. In addition, $10 \%$ cyclic strain was selected for our studies as this strain level is within the range of normal physiological conditions. To investigate SMC responses to both physiological cyclic strain and growth factors, SMC proliferation and gene expression were determined using PicoGreen DNA assays and cDNA microarrays (Affymetrix). 


\section{MATERIALS AND METHODS}

\subsection{Concentration of Growth Factor Used in Studies}

Human Aortic Smooth Muscle Cells (HASMC, Cascade Biologics, OR) were grown and maintained at $37^{\circ} \mathrm{C}$ in Dulbecco's Modified Eagle Medium (DMEM) (Invitrogen, NY), supplemented with $10 \%$ fetal bovine serum (FBS) (HyClone, UT). Cells between passages 5-10 were seeded at $10^{4}$ cells $/ \mathrm{cm}^{2}$ in 24 -well plates and fed quiescent media (DMEM supplemented with 2\% FBS) for 2 days. On day 3, cells were fed with different concentrations $(0-90 \mathrm{ng} / \mathrm{ml})$ of the growth factor (bFGF, TGF- $\beta$ or PDGF - all three isoforms) in quiescent media. After 72 hours of exposure, PicoGreen DNA assay was performed to generate a growth curve to determine the optimal concentration of each growth factor.

\subsection{SMC Proliferation Studies}

Cells were seeded at $10^{4}$ cells $/ \mathrm{cm}^{2}$ on type I collagencoated flexible membranes and grown for two days in quiescent media. Cells were exposed to cyclic strain (10\% strain at 60 cycles/min) by the FlexCell cyclic strain system in the presence or absence of growth factors at their optimal concentrations ( $30 \mathrm{ng} / \mathrm{ml}$ for bFGF, $15 \mathrm{ng} / \mathrm{ml}$ for TGF- $\beta$ and $15 \mathrm{ng} / \mathrm{ml}$ for PDGF-AB) for 3 days. After experiments, cells were lysed with $1 \%$ Triton X-100 and total cell DNA was analyzed using PicoGreen DNA assay (Molecular Probes) following the manufacturer's instructions. HASMCs cultured on membranes and not subjected to cyclic strain served as static controls.

\subsection{RNA Isolation and Microarray Analysis}

After exposure to cyclic strain with or without bFGF, TGF- $\beta$ and PDGF-AB, HASMCs were rinsed quickly with cold PBS and total RNA was isolated using TRIZOL reagent (Invitrogen) according to the manufacturer's instructions. Qualities of RNA samples were determined by spectrophotometric analysis (OD 260/280) and agarose gel electrophoresis as described previously [30]. Microarray
(Affymetrix) processing of RNA samples was done at Microarray Facility in the Center for Integrated BioSystems at Utah State University. After processing, microarrays were scanned for gene expression using microarray analysis suite software (Affymetrix). Bioconductor tools [31] were used to apply both nonspecific and specific filters. The nonspecific filter identified genes with coefficient of variance (sd/mean, taken across all arrays) between 0.3 and 10. A specific filter was applied to these genes, restricting attention to those involved in specific cellular (proliferation, inflammation, and apoptosis) and molecular (signal transduction) function gene ontologies. After filtering, genes with absolute fold change of 2 or more were selected for further investigation. Those selected genes were clustered and their functions in the various signaling pathways were analyzed using the online tool DAVID (Database for Annotation, Visualization, and Integrated Discovery) and the KEGG (Kyoto Encyclopedia of Genes and Genomes).

\subsection{Statistical Analysis}

Analysis of the results was performed using t-tests with $\mathrm{p}$ $<0.05$. For each study, the sample size was 3-6 $(n=3-6)$ and the results are presented as mean \pm standard deviation (SD).

\section{RESULTS}

\subsection{Effects of Growth Factors (bFGF, TGF- $\beta$ and PDGF) on SMC Proliferation}

For pilot studies, different concentrations $(0-90 \mathrm{ng} / \mathrm{ml})$ of bFGF, TGF- $\beta$ and the three isoforms (-AA, -BB and $-\mathrm{AB}$ ) of PDGF were investigated for optimal concentration for SMCs growth. We found maximal proliferation of SMCs at a concentration of $15 \mathrm{ng} / \mathrm{ml}$ of TGF- $\beta$, PDGF-AB and PDGFAA while maximum proliferation was seen at concentrations of $30 \mathrm{ng} / \mathrm{ml}$ of $\mathrm{bFGF}$ and $60 \mathrm{ng} / \mathrm{ml}$ of PDGF-BB. In case of PDGF, the isoform PDGF-AB showed the highest efficacy by exhibiting approximately $80 \%$ more SMC proliferation compared to the static controls while the isoforms PDGF-BB and PDGF-AA both showed about $20 \%$ more proliferation

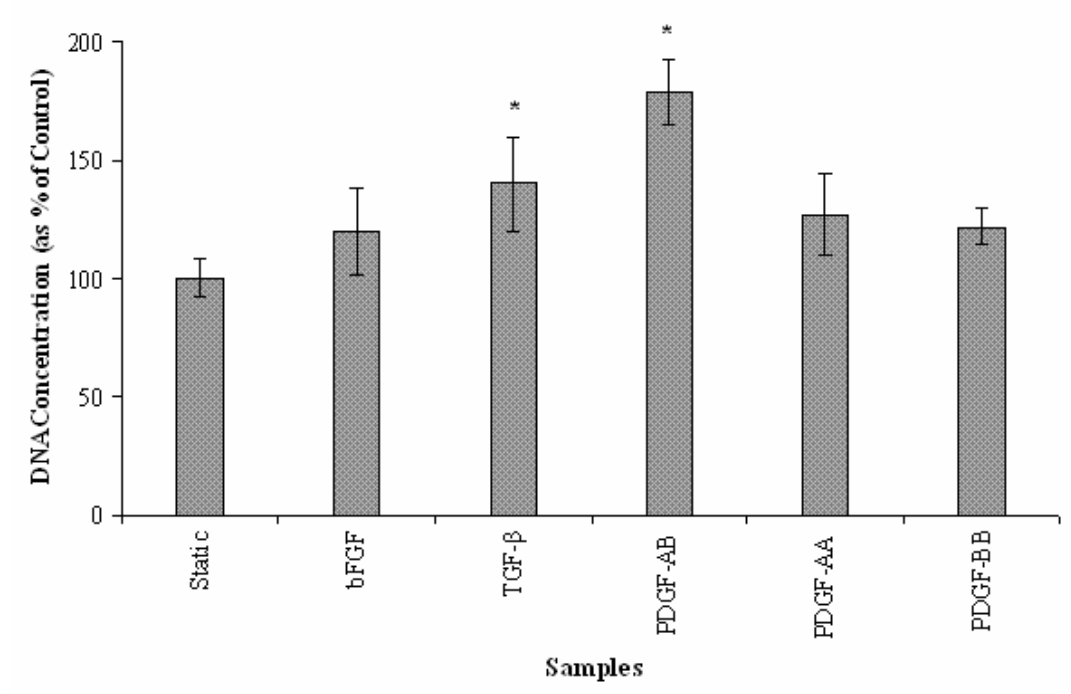

Fig. (1). Effect of the growth factors bFGF, TGF- $\beta$ and the three isoforms of PDGF on SMC proliferation under static conditions. (n=6; *: $p$ $<0.05$ vs. static controls). 
than the static control. With TGF- $\beta$, SMCs exhibited about $40 \%$ increase in growth and with bFGF the increase in growth was about $30 \%$. All the growth factors (bFGF, TGF$\beta$ and PDGF) increased the proliferation of SMCs after 3 days in culture (Fig. 1), indicating that these growth factors exhibit a positive effect on SMCs growth.

\subsection{Effects of Cyclic Strain and Growth Factors (bFGF, TGF- $\beta$ and PDGF) on SMC Proliferation}

As indicated in Fig. (2), physiological level of cyclic strain $(10 \%)$ significantly reduced SMC proliferation $(\sim 60 \%$ of the static controls, $\mathrm{p}<0.05)$. However, treatment with bFGF, TGF- $\beta$ and PDGF while cells were under cyclic strain showed a positive influence on SMC growth when compared to cells exposed to cyclic strain only $(p<0.05)$. TGF- $\beta$ and PDGF-AB in particular showed $~ 90 \%$ SMC proliferation in comparison to $60 \%$ for SMCs exposed to only cyclic strain. An interesting finding was that PDGF isoforms exhibited different effects on SMC proliferation on exposure to cyclic strain. Under physiological cyclic strain, PDGF-AA further reduced SMC proliferation $(\sim 45 \%)$ while PDGF-AB and PDGF-BB increased SMC proliferation compared to the static control and cyclic strain. Between the two, PDGF-AB still showed the highest efficacy for enhancing cell growth, showing even higher cell proliferation than the static control. Although these growth factors diminish the behavior of cyclic strain-reduced cell growth, SMC growth is similar with the static samples excluding PDGF-AA (Figs. 1, 2).

\subsection{Effects of Cyclic Strain on Gene Expressions of SMC}

After filtering, microarray data showed that 11 genes were up-regulated and 7 genes were down-regulated when cells are exposed to $10 \%$ cyclic strain compared to cells under static controls (Table 1). Under cyclic strain, SOCS3 (an inhibitor in the JAK-STAT signaling pathway) was down-regulated ( $\sim 3$ fold). Expression of a receptor of tumor necrosis factor (TNF) - TNFRSF19 and the Fas - Fas apoptotic inhibitory molecule 2 (anti-apoptosis) were also reduced. Also, three anti-apoptotic genes (FAIM2, SERPINB9 and SOCS3) were down-regulated by a factor of two to three. These results indicate that cyclic strain alters the expression of some genes associated with apoptosis that lead to decreased SMC proliferation.

\subsection{Effects of Growth Factors bFGF, TGF- $\beta$ and PDGF- AB on Gene Expression of SMCs Under Cyclic Strain}

Comparing the results of the effect of cyclic strain and growth factor (bFGF, TGF- $\beta$ or PDGF-AB) on gene expression with those of the cells exposed to $10 \%$ cyclic strain, an increase in number of genes regulated (Table 2-4) was observed. For example, there was an increased upregulation of various interleukins (ILs), especially both IL-1 $\alpha$ and IL-1 $\beta$ when cyclic strain was combined with growth factors (Table 2-4). Also, the expression of various factors (prostaglandin, VEGF and EGFR) was also induced. Furthermore, combination of cyclic strain with bFGF or TGF- $\beta$ also increased down-regulation of genes involved in suppression of cytokine signaling (SOCS3, SOCS2), apoptosis and regulation of cell growth (tumor necrosis factors, heat shock protein $1 \mathrm{~B}$, serin peptidase inhibitor) and molecules related to cell adhesion like collagen type 1 . When SMC's were exposed to PDGF-AB under cyclic strain, EREG, a gene encoding epirgulin (a member of the epidermal growth factor family), and VEGF, which encodes the vascular endothelial growth factor, were up-regulated three folds. In contrast, cyclic strain alone regulated only a small number of bioactive genes in SMCs compared to static controls (Table 1).

\subsection{Effects of both Cyclic Strain and Growth Factors on Signaling Pathways in SMCs}

Both cyclic strain and growth factors regulated several signaling molecules in SMCs in our studies. Results from DAVID and KEGG charts indicated both cyclic strain and growth factors regulated various molecules involved with cytokine-cytokine receptor interactions, MAPK and JAKSTAT signaling pathways (Figs. 3, 4). For example, JNK and p38 MAPK were found as potential signaling pathways when cells were exposed to both cyclic strain and growth factors (Fig. 3). Genes involved with regulation of cell

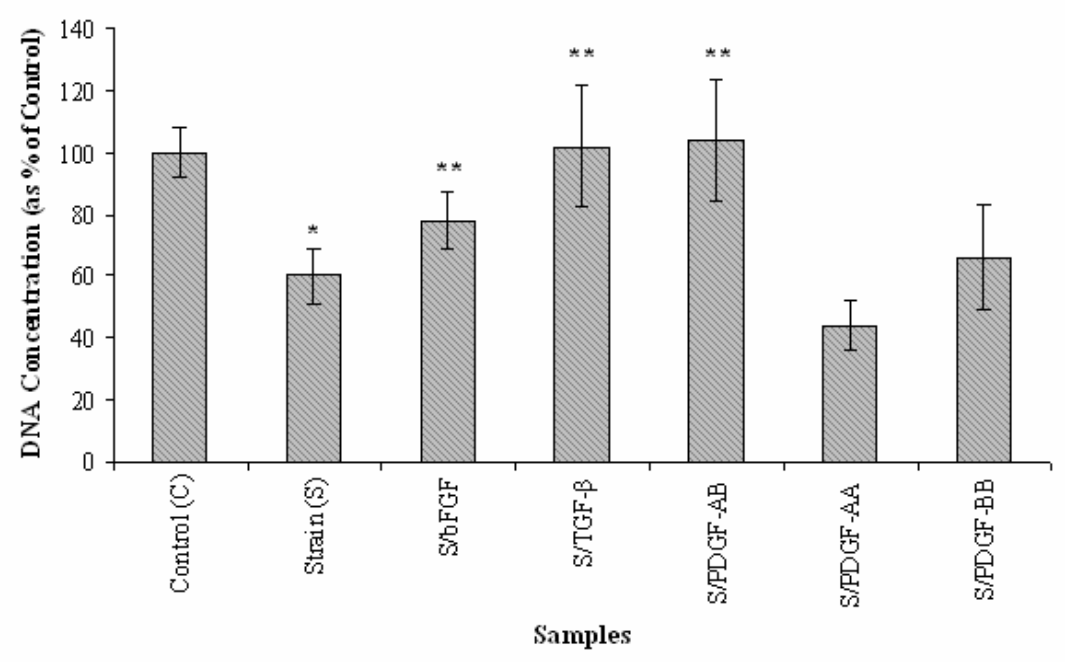

Fig. (2). Effects of bFGF, TGF- $\beta$ and three PDGF isoforms on SMC proliferation under cyclic strain. (n=6; *: p < 0.05 vs. static control (C); $* *: \mathrm{p}<0.05$ vs. cyclic strain (S)). 
Table 1. Effects of Cyclic Strain on Gene Expression in SMCs Versus Static Culture

\begin{tabular}{|c|c|c|c|}
\hline FUNCTION & GENE & DESCRIPTION & FOLD CHANGE \\
\hline \multirow[t]{5}{*}{ Inflammation } & IL1RN & interleukin 1 receptor antagonist & 2.86 \\
\hline & HDAC9 & Histone deacetylase 9 & 2.20 \\
\hline & IL1RN & interleukin 1 receptor antagonist & 2.17 \\
\hline & IRF7 & interferon regulatory factor 7 & -2.23 \\
\hline & CXCL12 & chemokine (C-X-C motif) ligand 12 & -2.86 \\
\hline \multirow[t]{2}{*}{ Proliferation } & IL1B & interleukin 1 , beta & 3.24 \\
\hline & IL1A & interleukin 1, alpha & 2.83 \\
\hline \multirow[t]{3}{*}{ Apoptosis } & HIPK2 & homeodomain interacting protein kinase 2 & 1.99 \\
\hline & $\mathrm{F} 2 \mathrm{R}$ & coagulation factor II (thrombin) receptor & -1.99 \\
\hline & TNFRSF19 & TNF receptor superfamily, member 19 & -2.19 \\
\hline \multirow[t]{4}{*}{ Anti-Apoptosis } & SERPINB2 & $\begin{array}{l}\text { serpin peptidase inhibitor, clade B (ovalbumin), member } \\
2\end{array}$ & 2.05 \\
\hline & SERPINB9 & serpin peptidase inhibitor, clade B, member 9 & -2.06 \\
\hline & SOCS3 & suppressor of cytokine signaling 3 & -3.12 \\
\hline & FAIM2 & Fas apoptotic inhibitory molecule 2 & -3.33 \\
\hline
\end{tabular}

Table 2. Differential Gene Expression in SMCs Exposed to Cyclic Strain and bFGF Versus Static Culture

\begin{tabular}{|l|l|l|l|}
\hline \multirow{3}{*}{ FUNCTION } & GENE & DESCRIPTION & FOLD CHANGE \\
\hline \hline \multirow{5}{*}{ Inflammation } & IL1RN & interleukin 1 receptor antagonist & 2.88 \\
\cline { 2 - 4 } & CXCL5 & chemokine (C-X-C motif) ligand 5 & 2.30 \\
\cline { 2 - 4 } & CCL8 & chemokine (C-C motif) ligand 8 & 2.23 \\
\cline { 2 - 4 } & MGLL & monoglyceride lipase & 2.22 \\
\cline { 2 - 4 } & GPR68 & G protein-coupled receptor 68 & -2.30 \\
\cline { 2 - 4 } & TNF $\alpha$ IP6 & Tumor Necrosis Factor alpha-induced protein 6 & -3.42 \\
\cline { 2 - 4 } & CXCL12 & chemokine (C-X-C motif) ligand 12 & -2.41 \\
\cline { 2 - 4 } & IL1R1 & interleukin 1 receptor, type I & 3.80 \\
\hline \multirow{5}{*}{ Proliferation } & IL1 $\beta$ & interleukin 1, beta & 3.54 \\
\cline { 2 - 4 } & EREG & epiregulin & 3.01 \\
\cline { 2 - 4 } & EGFR & epidermal growth factor receptor & -2.08 \\
\cline { 2 - 4 } & TP53 & tumor protein p53 (Li-Fraumeni syndrome) & -2.23 \\
\cline { 2 - 4 } & SERPINE2 & serpin peptidase inhibitor, clade E, member 2 & \\
\hline
\end{tabular}


(Table 2). Contd.....

\begin{tabular}{|c|c|c|c|}
\hline FUNCTION & GENE & DESCRIPTION & FOLD CHANGE \\
\hline \multirow[t]{7}{*}{ Apoptosis } & CASP1 & caspase 1 , apoptosis-related cysteine peptidase & -2.01 \\
\hline & PLAGL1 & pleiomorphic adenoma gene-like 1 & -2.15 \\
\hline & PLAGL1 & pleiomorphic adenoma gene-like 1 & -2.27 \\
\hline & TPD52L1 & tumor protein D52-like 1 & -2.55 \\
\hline & TPD52L1 & tumor protein D52-like 1 & -2.94 \\
\hline & SULF1 & sulfatase 1 & -3.58 \\
\hline & TNFRSF11B & TNF-receptor superfamily, member $11 \mathrm{~b}$ & -4.23 \\
\hline \multirow[t]{2}{*}{ Anti-Apoptosis } & BCL2A1 & BCL2-related protein A1 & 2.99 \\
\hline & ANGPTL4 & angiopoietin-like 4 & 2.85 \\
\hline
\end{tabular}

Table 3. Differential Gene Expression in SMCs Exposed to Cyclic Strain and TGF $\beta$ Versus Static Culture

\begin{tabular}{|c|c|c|c|}
\hline FUNCTION & GENE & DESCRIPTION & FOLD CHANGE \\
\hline \multirow[t]{19}{*}{ Inflammation } & PTGS2 & prostaglandin-endoperoxide synthase 2 & 4.96 \\
\hline & VEGF & vascular endothelial growth factor & 3.42 \\
\hline & $\operatorname{IL} 1 \beta$ & interleukin 1 , beta & 2.37 \\
\hline & OLR1 & oxidised low density lipoprotein & 2.72 \\
\hline & EGFR & epidermal growth factor receptor & 2.32 \\
\hline & SMURF2 & SMAD specific E3 ubiquitin protein ligase 2 & 2.26 \\
\hline & IL6 & interleukin 6 (interferon, beta 2) & 2.25 \\
\hline & AOX1 & aldehyde oxidase 1 & -2.13 \\
\hline & PTX3 & pentraxin-related gene & -2.15 \\
\hline & NFATC4 & nuclear factor of activated T-cells & -2.20 \\
\hline & CXCL2 & chemokine (C-X-C motif) ligand 2 & -2.31 \\
\hline & $\mathrm{C} 3$ & complement component 3 & -2.42 \\
\hline & CD14 & CD14 antigen & -2.47 \\
\hline & IL1R1 & interleukin 1 receptor, type I & -2.53 \\
\hline & BDKRB2 & bradykinin receptor $\mathrm{B} 2$ & -2.67 \\
\hline & IL17D & interleukin 17D & -2.69 \\
\hline & IL1R1 & interleukin 1 receptor, type I & -2.71 \\
\hline & IL17D & interleukin 17D & -2.84 \\
\hline & CXCL12 & chemokine (C-X-C motif) ligand 12 & -4.30 \\
\hline \multirow[t]{2}{*}{ Proliferation } & $\operatorname{IL} 1 \alpha$ & interleukin 1 , alpha & 3.86 \\
\hline & EREG & Epiregulin (negative regulation of cell proliferation) & 2.05 \\
\hline \multirow[t]{2}{*}{ Apoptosis } & TP53 & tumor protein p53 (Li-Fraumeni syndrome) & -2.29 \\
\hline & CD14 & CD14 antigen & -2.47 \\
\hline \multirow[t]{2}{*}{ Anti-Apoptosis } & BCL2A1 & BCL2-related protein A1 & 2.59 \\
\hline & RASA1 & RAS p21 protein activator (GTPase activating protein) 1 & 2.08 \\
\hline
\end{tabular}


Table 4. Differential Gene Expression in SMCs Exposed to Cyclic Strain and PDGF-AB Versus Static Culture

\begin{tabular}{|c|c|c|c|}
\hline FUNCTION & GENE & DESCRIPTION & FOLD CHANGE \\
\hline \multirow[t]{9}{*}{ Inflammation } & PTGS2 & prostaglandin-endoperoxide synthase 2 & 7.44 \\
\hline & IL1A & interleukin 1 , alpha & 5.08 \\
\hline & CCL20 & chemokine (C-C motif) ligand 20 & 4.98 \\
\hline & IL8 & interleukin 8 & 3.74 \\
\hline & IL6 & interleukin 6 (interferon, beta 2) & 3.31 \\
\hline & IL1RN & interleukin 1 receptor antagonist & 2.48 \\
\hline & AOX1 & aldehyde oxidase 1 & -2.6 \\
\hline & TNFAIP8 & TNF, alpha-induced protein 8 & -2.47 \\
\hline & $\mathrm{C} 3$ & complement component 3 & -2.34 \\
\hline \multirow[t]{2}{*}{ Proliferation } & EREG & Epiregulin & 3.1 \\
\hline & VEGF & vascular endothelial growth factor & 3.07 \\
\hline \multirow[t]{2}{*}{ Apoptosis } & TP53 & tumor protein $\mathrm{p} 53$ & -4.81 \\
\hline & CASP1 & caspase 1 & -4.47 \\
\hline
\end{tabular}

apoptosis were also found in cells exposed to both cyclic strain and growth factors. For instance, genes such as SOCS2 and SOCS3 (suppressor of cytokine signaling) were regulated in most of the experimental conditions compared to static controls (Table 2-4).

\section{DISCUSSION AND LIMITATIONS}

To date, combined effects of cyclic strain and growth factors have not been well-studied. Our current study reveals that physiological cyclic strain and growth factors regulate cell proliferation and gene expression in SMCs. Compared to cells exposed to cyclic strain alone, cells exposed to cyclic strain and bFGF, TGF- $\beta$ or PDGF-AB exhibited significant SMC proliferation, as shown by our results. Microarray analysis of these SMCs showed the alteration of various genes such as SOCS3 (an inhibitor in the JAK-STAT signaling pathway), TNF and FAIM2, and the potential involved mechanisms including MAPK, JAK-STAT and cytokine-cytokine receptor interaction signaling pathways.

Consistent with previous observations, our results demonstrate that cyclic strain at physiological level $(10 \%$ strain) causes a significant decrease in cell proliferation compared to static culture. Physiological cyclic strain decreases SMC growth by inducing apoptosis through Notch signaling pathways [7]. Other studies have also shown that mitogen-activated protein kinases (MAPK) are activated when cultured SMCs are exposed to stretch leading to cell apoptosis [32-35]. Conversely, pathological stretch has been shown to initiate signaling pathways of nuclear factor-kappa $\mathrm{B}(\mathrm{NF}-\kappa \mathrm{B})$ and reactive oxygen species (ROS), leading to SMC proliferation, stress-induced inflammation and apoptosis [33, 36-38].

While physiological cyclic strain reduced SMC proliferation significantly, adding growth factors with cyclic strain diminishes this behavior in our studies. Of the studied growth factors, TGF- $\beta$, PDGF-AB and bFGF have the most positive effect on SMC proliferation, and their role in SMC proliferation is well documented [16, 39-43]. TGF- $\beta$ and PDGF-AB induced greater SMC proliferation compared to bFGF when exposed to cyclic strain, suggesting that they may share the same signaling pathways with cyclic strain. Other studies also found that bFGF induced less cell proliferation compared to other growth factors (PDGF-AB and PDGF-BB) [44]. 


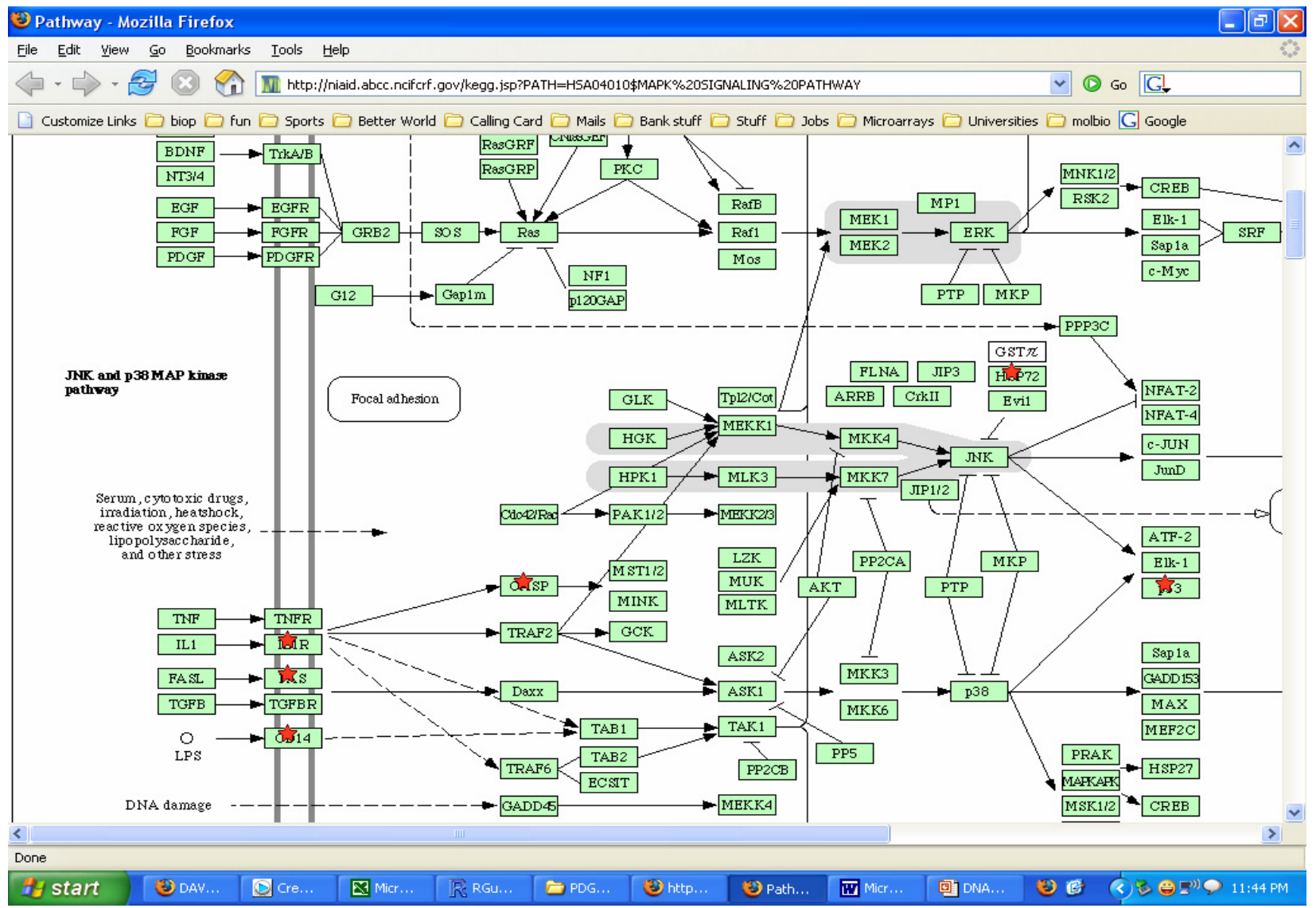

Fig. (3). Potential roles of MAPK pathways involved with cells exposed to both cyclic strain and growth factors bFGF and TGF $\beta$. *indicates molecules that may be involved in the process using KEGG software analysis.

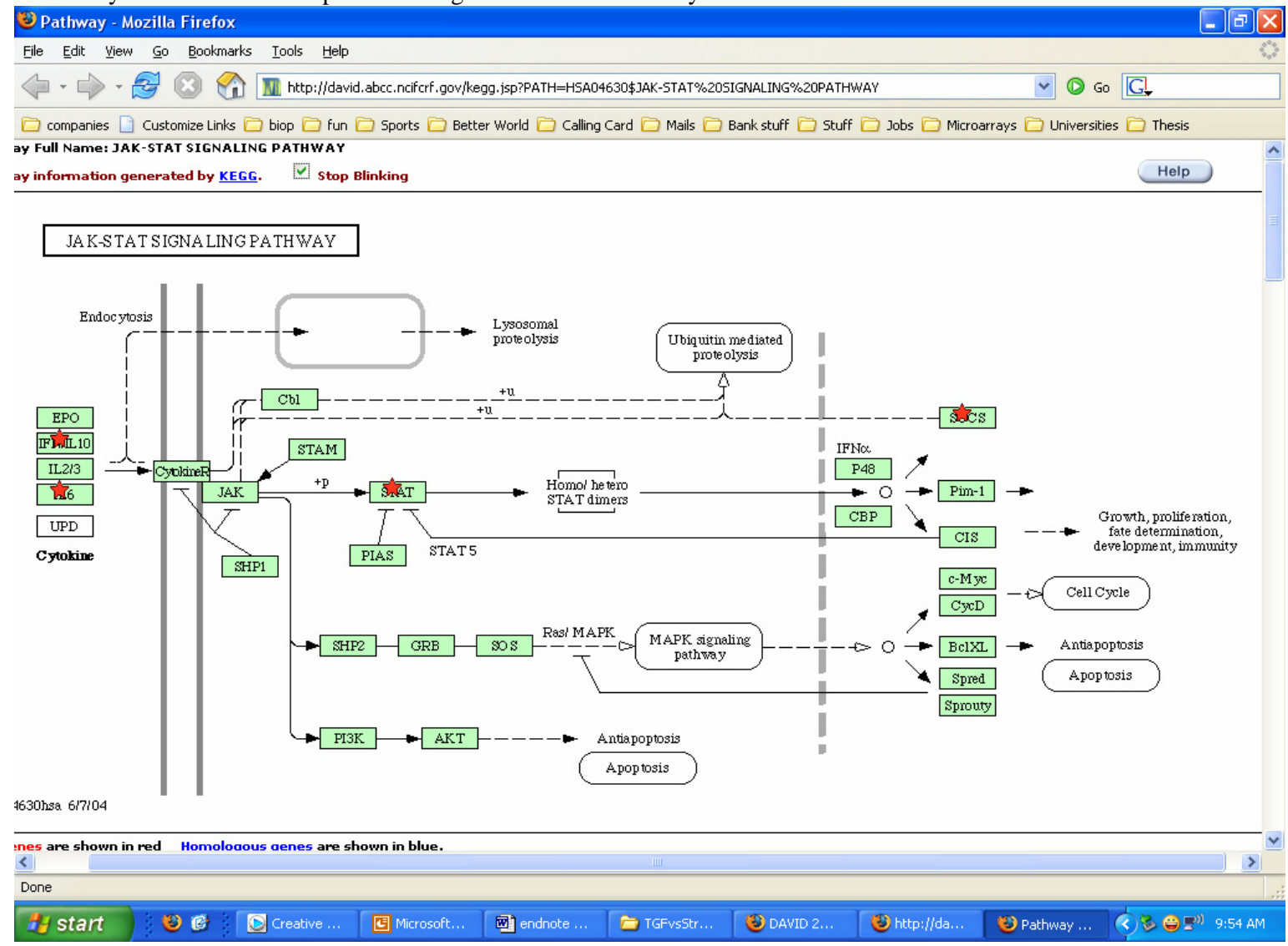

Fig. (4). Potential roles of JAK-STAT pathways involved with cells exposed to both cyclic strain and growth factors bFGF and TGF $\beta$. *indicates molecules that may be involved in the process using KEGG software analysis. 
It has been shown that cyclic strain also regulates SMC responses through a number of other cellular signaling transduction pathways like extracellular signal-regulated kinase 1/2 (ERK1/2) [19], ROS [5], calcium ion channels [45], cytoskeletal elements, focal adhesion proteins, Gprotein coupled receptors and TNF-kB [5]. Some experimental evidence suggests that several factors, including cyclic strain, growth factors and vasoactive substances, [35, 46-50] are responsible for SMC proliferation. For example, chemical factors (Ang II and thrombin) demonstrate additive effects with cyclic strain on gene regulation [8,39]. In vivo studies have found that circulating growth factors along with increased cyclic strain cause vascular wall remodeling in hypertensive humans and animals $[51,52]$. It is possible that cyclic strain might act as a co-mitogen with other artherogenic risk factors such as growth factors thereby altering gene expression and promoting SMC proliferation throughout intimal thickening. Therefore, it is important to investigate the effects of both cyclic strain and growth factors on SMC responses.

The microarray results demonstrate much exciting progress in our understanding of SMC responses to both cyclic strain and growth factors. However, a major challenge of the microarray analysis is to integrate the large data of gene expression to obtain the useful biomarkers or molecules and signaling pathways. In our study, we filtered the genes on the basis of cell proliferation, apoptosis, inflammation, and signal transduction. After filtering, our results showed that cyclic strain when combined with each of the growth factors, bFGF, PDGF-AB and TGF- $\beta$, altered the expression of several bioactive genes and signaling molecules, as described in detail below.

\subsection{Genes Related to Inflammation Responses}

Since the genes related to inflammation responses such as interleukins (ILs) have been shown to play an important role in regulation of SMC growth, these genes were selected in our studies. For instance, some cytokines have been shown to inhibit endothelial cell growth while stimulating SMC growth [53]. Genes involved in inflammatory response, especially the interleukins, are altered in SMCs exposed to both cyclic strain and growth factors in our studies. As a surprise finding, among all the interleukins, IL$1 \beta$ was up-regulated when cyclic strain was combined with growth factors (bFGF $\sim 4$ fold increase, TGF- $\beta \sim 2$ fold, Tables 2-3). Interestingly, IL-1 has been reported to promote SMC proliferation $[54,55]$ and induces the transformation of vascular SMCs into foam cells by an increased uptake of unmodified LDL [56]. Besides IL-1, IL-6 that can stimulate SMC growth [57] was also induced $\sim 2$ fold in cells exposed to both cyclic strain and TGF- $\beta$ compared to those of static controls. High levels of cyclic strain (up to 20\% strain) have been shown to induce the expression of IL-6, but not other interleukins (IL-1a, IL-1b, IL-10, IL-12 and IL-18) in previous studies [33]. These observations suggest the involvement of biomechanical factors with inflammation responses. In addition to ILs, a 5-fold increase in PTGS2 (prostaglandin-endoperoxide synthase 2), a gene involved in inflammatory response and cell motility as well as in glucose homeostasis [58], has been observed when SMCs are exposed to both cyclic strain and growth factor TGF- $\beta$ or both cyclic strain and growth factor PDGF-AB.

\subsection{Genes Involved with ECM and Cell Adhesion}

ECM proteins play a major role in cell adhesion and subsequent cell proliferation. Collagen, a major ECM protein found in plaques, is also secreted by synthetic phenotypic SMCs. Mechanical forces (cyclic strain/ stretch) have been found to produce an increase in collagen synthesis and other ECM proteins in cultured SMC [59]. Physiological cyclic strain increases the expression of collagen 2-fold only, as per our results. When SMCs were exposed to both bFGF and $10 \%$ cyclic strain, expression of collagen 1 was downregulated by 4 times compared to static controls. Although ECM proteins like collagen can regulate cell adhesion, it is also worth to note that changes in collagen expression have been found to be independent with proliferation of SMCs by bFGF as shown by previous studies [60].

\subsection{Genes Regulating Cell Proliferation and Apoptosis}

On exposure to cyclic strain, SMCs exhibited a decrease in cell proliferation. Both SOCS and STAT, which are involved in intracellular signaling cascade of cell apoptosis [61], were found in cells exposed to both cyclic strain and growth factors (Fig. 4). Under cyclic strain, a 2 to 3 -fold down regulation in the expression of anti-apoptotic genes SERPINB9 and FAIM2 was observed. The down-regulation of these anti-apoptotic genes could possibly induce SMC apoptosis and result in less cell proliferation under cyclic strain than the static control. These results are in accordance with previous observations by Morrow et al. who found that physiological level cyclic strain inhibits SMC growth while enhancing SMC apoptosis [7]. In contrast, Chapman et al. claimed that cyclic stretch inhibited SMC growth only by blocking cell cycle progression without excess apoptosis [6]. The differences in findings might be due to the different cyclic strain exposure time and apoptosis detecting methods used. Reduction of endogenous FAIM expression could induce caspase-8 activation and cell apoptosis [62]. SERPINB9, also known as Proteinase Inhibitor 9 (PI-9), inhibits caspase-1 and thereby inhibits apoptosis [63].

Cyclic strain and growth factors were also found to alter several genes involved with cell proliferation and apotosis such as vascular endothelial growth factor (VEGF), EREG (a gene encoding epirgulin and member of the epidermal growth factor family) and heat shock protein. The increased expression of these mitogenic factors certainly could enhance cell proliferation. In addition, the overall apoptosis/anti-apoptosis gene panel was inclined to inhibit cell apoptosis, in other words, to enhance cell proliferation. VEGF plays an important role in various biological and cellular processes in several pathological conditions [64]. VEGF is also involved in inhibiting apoptosis in SMCs in atherosclerosis [65]. VEGF was modestly induced to 1.9fold by $4 \%$ strain at 12 and 24 hours in other studies [66]. TGF- $\beta$ and PDGF-AB increased VEGF expression ( $\sim 3$ fold $)$ when combined with strain. An increased up regulation of the genes epiregulin and EGFR, which are responsible for proliferation, was also seen in our studies.

Different apoptotic genes, CASP1, CASP8, various tumor protein family genes and CARD10 were downregulated three to five times, while genes encoding the antiapoptotic factors, such as BCL2-related protein A1 (BCL2A1), were up-regulated. BCL2A1 is a member of the 
BCL-2 family and has been shown to retard apoptosis in various cell lines [67]. In addition to mitogenic factors and apoptotic/anti-apoptotic genes, the gene profile of cytokines is interesting to note. Several interleukins, which are known for their proliferative effects on SMCs, including interleukin$1 \alpha(\mathrm{IL}-1 \alpha)$ [55, 68], interleukin-1 $\beta$ (IL-1 $\beta$ ) [54], interleukin6 (IL-6), and interleukin-8 (IL-8) [69], were also upregulated.

Heat shock proteins (hsp), involved in anti-apoptosis, protect SMCs from death and in turn stabilize the arterial plaques [70]. Cyclic strain levels at 10, 15 and 20\% strain induced expression of hsp70 significantly compared to static controls (upto 5-fold) [71]. Cyclic strain and growth factors repressed HSPA1B gene expression by 2-folds while increasing the HSPA5 expression by 2 -folds. It is hard to speculate that HSP plays any role in the altered proliferation of SMCs by both cyclic strain and growth factors because the induction of HSPA1B by the process is not high (just 2folds) and is balanced with the regression of HSPA5.

\subsection{Signal Transduction Genes}

The gene expression results shows that when cyclic strain is combined with growth factors, many genes involved in signal transduction pathways are modulated. For example, genes such as SOCS2 and SOCS3 were repressed along with STAT1 in most of our experimental conditions. Both SOCS and STAT are involved in intracellular signaling cascade and anti-apoptosis. Recent studies show the involvement of SOCS3 in down-regulating the hypoxia induced PASMC proliferation by $50 \%$ [61]. In addition, SMURF2, shown to be involved in apoptosis by recruiting $\mathrm{Rb}$ and $\mathrm{p} 53$ pathways and in TGF- $\beta$ receptor signaling [72], showed a 2-fold increase in expression when exposed to cyclic strain and TGF- $\beta$.

Results from DAVID and KEGG charts indicated both cyclic strain and growth factors regulated various molecules involved with pathways such as cytokine-cytokine receptor interactions, Mitogen-Activated Protein Kinase (MAPK) and Janus kinases-signal transducers and activators of transcription (JAK-STAT) signaling pathways. Although there is no study showing the involvement of cytokinecytokine receptor interactions in the cyclic strain regulation, various MAPK and JAK-STAT signaling molecules have been found to be involved with the effects of cyclic strain on SMCs [34, 73-76]. Previous studies demonstrate that STAT3 , ERK1/2, and Src are involved in mediating the effects of cyclic strain on vascular SMCs [73]. Other studies also find cyclic strain-induced IL-6 expression in SMCs via Ras/Rac1/p38 MAPK/NF-kB signaling pathways [33].

Though the project collected a vast amount of gene expression data from cDNA microarray experiments, we had to use filtering mechanisms based on gene oncology. In addition, we did not investigate the effects of both pathological cyclic strain and growth factors on SMC responses in this current study. Despite these limitations, results from this project might provide insight into the biological aspects of SMC responses to various stimuli. Future studies will investigate various levels of biochemicals and physiological and pathological cyclic strain on SMC responses. A further understanding of molecular mechanisms involved in these SMC responses will also have important clinical interventions that can modify SMC proliferation, thereby reducing the risk for cardiovascular diseases.

\section{REFERENCES}

[1] M. A. Gimbrone, Jr., J. N. Topper, T. Nagel, K. R. Anderson, and G. Garcia-Cardena, "Endothelial dysfunction, hemodynamic forces, and atherogenesis," Ann. N.Y. Acad. Sci., vol. 902, pp. 230-9, discussion 239-40, May 2000.

[2] S. Q. Liu, M. M. Moore, and C. Yap, "Prevention of mechanical stretch-induced endothelial and smooth muscle cell injury in experimental vein grafts," J. Biomech. Eng., vol. 122, pp. 31-8, Feb 2000.

[3] H. M. Loree, R. D. Kamm, R. G. Stringfellow, and R. T. Lee, "Effects of fibrous cap thickness on peak circumferential stress in model atherosclerotic vessels," Circ. Res., vol. 71, pp. 850-8, Oct 1992.

[4] N. Resnick, H. Yahav, A. Shay-Salit, M. Shushy, S. Schubert, L. C. Zilberman, and E. Wofovitz, "Fluid shear stress and the vascular endothelium: for better and for worse," Prog. Biophys. Mol. Biol., vol. 81, pp. 177-99, Apr 2003

[5] K. Hishikawa, B. S. Oemar, Z. Yang, and T. F. Luscher, "Pulsatile stretch stimulates superoxide production and activates nuclear factor-kappa B in human coronary smooth muscle," Circ. Res., vol. 81, pp. 797-803, Nov 1997.

[6] G. B. Chapman, W. Durante, J. D. Hellums, and A. I. Schafer, "Physiological cyclic stretch causes cell cycle arrest in cultured vascular smooth muscle cells," Am. J. Physiol. Heart Circ. Physiol., vol. 278, pp. H748-54, March 2000.

[7] D. Morrow, C. Sweeney, Y. A. Birney, P. M. Cummins, D. Walls, E. M. Redmond, and P. A. Cahill, "Cyclic strain inhibits Notch receptor signaling in vascular smooth muscle cells in vitro," Circ. Res., vol. 96, pp. 567-75, March 2005.

[8] B. Williams, "Mechanical influences on vascular smooth muscle cell function," J. Hypertens., vol. 16, pp. 1921-9, Dec 1998.

[9] M. A. Reidy, "Neointimal proliferation: the role of basic FGF on vascular smooth muscle cell proliferation," Thromb. Haemost., vol. 70, pp. 172-6, July 1993.

[10] M. A. Reidy, J. Fingerle, and V. Lindner, "Factors controlling the development of arterial lesions after injury," Circulation, vol. 86, pp. III43-6, Dec 1992.

[11] G. C. Cheng, W. H. Briggs, D. S. Gerson, P. Libby, A. J. Grodzinsky, M. L. Gray, and R. T. Lee, "Mechanical strain tightly controls fibroblast growth factor-2 release from cultured human vascular smooth muscle cells," Circ. Res., vol. 80, pp. 28-36, Jan 1997.

[12] A. Khanna, "Concerted effect of transforming growth factor-beta, cyclin inhibitor p21, and c-myc on smooth muscle cell proliferation," Am. J. Physiol. Heart Circ. Physiol., vol. 286, pp. H1133-40, Mar 2004.

[13] A. Orlandi, P. Ropraz, and G. Gabbiani, "Proliferative activity and alpha-smooth muscle actin expression in cultured rat aortic smooth muscle cells are differently modulated by transforming growth factor-beta 1 and heparin," Exp. Cell Res., vol. 214, pp. 528-36, Oct 1994.

[14] T. Matsui, "[PDGF system in vascular smooth muscle cell proliferation]," Nippon Rinsho, vol. 51, pp. 1656-62, Jun 1993.

[15] A. D. Hughes, G. F. Clunn, J. Refson, and C. Demoliou-Mason, "Platelet-derived growth factor (PDGF): actions and mechanisms in vascular smooth muscle," Gen. Pharmacol., vol. 27, pp. 1079-89, Oct 1996.

[16] G. C. Cheng, P. Libby, A. J. Grodzinsky, and R. T. Lee, "Induction of DNA synthesis by a single transient mechanical stimulus of human vascular smooth muscle cells. Role of fibroblast growth factor-2," Circulation, vol. 93, pp. 99-105, Jan 11996.

[17] E. Wilson, Q. Mai, K. Sudhir, R. H. Weiss, and H. E. Ives, "Mechanical strain induces growth of vascular smooth muscle cells via autocrine action of PDGF," J. Cell Biol., vol. 123, pp. 741-7, Nov 1993.

[18] P. R. Standley, T. J. Obards, and C. L. Martina, "Cyclic stretch regulates autocrine IGF-I in vascular smooth muscle cells: implications in vascular hyperplasia," Am. J. Physiol., vol. 276, pp. E697-705, Apr 1999.

[19] H. Iwasaki, S. Eguchi, H. Ueno, F. Marumo, and Y. Hirata, "Mechanical stretch stimulates growth of vascular smooth muscle 
cells via epidermal growth factor receptor," Am. J. Physiol. Heart Circ. Physiol., vol. 278, pp. H521-9, Feb 2000.

[20] K. T. Nguyen, S. R. Frye, S. G. Eskin, C. Patterson, M. S. Runge, and L. V. McIntire, "Cyclic strain increases protease-activated receptor-1 expression in vascular smooth muscle cells," Hypertension, vol. 38, pp. 1038-43, Nov 2001.

[21] R. Kahlon, J. Shapero, and A. I. Gotlieb, "Angiogenesis in atherosclerosis," Can. J. Cardiol., vol. 8, pp. 60-4, Jan-Feb 1992.

[22] J. S. Ross, N. E. Stagliano, M. J. Donovan, R. E. Breitbart, and G. S. Ginsburg, "Atherosclerosis: a cancer of the blood vessels?," Am J. Clin. Pathol., vol. 116(Suppl), pp. S97-107, Dec 2001.

[23] J. G. Pickering, L. H. Chow, and C. M. Ford, "Basic fibroblast growth factor has potent selective effects on collagen gene expression by human Vascular Smooth Muscle cells," J. Am. Coll. Cardiol., vol. 25, p. 241A, 1995.

[24] M. W. Feinberg, M. K. Jain, F. Werner, N. E. Sibinga, P. Wiesel, H. Wang, J. N. Topper, M. A. Perrella, and M. E. Lee, "Transforming growth factor-beta 1 inhibits cytokine-mediated induction of human metalloelastase in macrophages," J. Biol. Chem., vol. 275, pp. 25766-73, Aug 182000.

[25] E. Lutgens, M. Gijbels, M. Smook, P. Heeringa, P. Gotwals, V. E. Koteliansky, and M. J. Daemen, "Transforming growth factor-beta mediates balance between inflammation and fibrosis during plaque progression," Arterioscler. Thromb. Vasc. Biol., vol. 22, pp. 97582, June 2002.

[26] G. Mercuro, and A. Cherchi, "[The vascular and metabolic mechanisms of the development of the atherosclerotic plaque]," Cardiologia, vol. 36, pp. 291-7, Dec 1991.

[27] F. Cipollone, M. Fazia, G. Mincione, A. Iezzi, B. Pini, C. Cuccurullo, S. Ucchino, F. Spigonardo, M. Di Nisio, F. Cuccurullo, A. Mezzetti, and E. Porreca, "Increased expression of transforming growth factor-beta1 as a stabilizing factor in human atherosclerotic plaques," Stroke, vol. 35, pp. 2253-7, Oct 2004.

[28] C. Giachelli, N. Bae, M. Almeida, D. Denhardt, C. Alpers, and S. Schwartz, "Osteopontin is elevated during neointima formation in rat arteries and is novel component of human atherosclerotic plaques," J. Clin. Invest., vol. 92, pp. 1686-1696, Oct 1993.

[29] T. Matsui, "Two platelet-derived growth factor receptors in vascular smooth muscle cells," Jpn. Circ. J., vol. 55, pp. 1027-35, Oct 1991.

[30] K. T. Nguyen, N. Shaikh, K. P. Shukla, S. H. Su, R. C. Eberhart, and L. Tang, "Molecular responses of vascular smooth muscle cells and phagocytes to curcumin-eluting bioresorbable stent materials," Biomaterials, vol. 25, pp. 5333-46, Oct 2004.

[31] Gentleman, Carey, Huber, Irizarry, and Dudoit, "Bioinformatics and Computational Biology Solutions Using R and Bioconductor," 2005.

[32] A. Negre-Salvayre, O. Vieira, I. Escargueil-Blanc, and R. Salvayre, "Oxidized LDL and 4-hydroxynonenal modulate tyrosine kinase receptor activity," Mol. Aspects Med., vol. 24, pp. 251-61, Aug-Oct 2003.

[33] A. Zampetaki, Z. Zhang, Y. Hu, and Q. Xu, "Biomechanical stress induces IL-6 expression in smooth muscle cells via Ras/Rac1-p38 MAPK-NF-kappaB signaling pathways," Am. J. Physiol. Heart Circ. Physiol., vol. 288, pp. H2946-54, June 2005.

[34] M. Mayr, C. Li, Y. Zou, U. Huemer, Y. Hu, and Q. Xu, "Biomechanical stress-induced apoptosis in vein grafts involves p38 mitogen-activated protein kinases," FASEB J., vol. 14, pp. 26170, Feb 2000.

[35] Y. Zou, Y. Hu, B. Metzler, and Q. Xu, "Signal transduction in arteriosclerosis: mechanical stress-activated MAP kinases in vascular smooth muscle cells (review)," Int. J. Mol. Med., vol. 1, pp. 827-34, May 1998.

[36] J. A. Leopold, and J. Loscalzo, "Cyclic strain modulates resistance to oxidant stress by increasing G6PDH expression in smooth muscle cells," Am. J. Physiol. Heart Circ. Physiol., vol. 279, pp. H2477-85, Nov 2000.

[37] H. Matsushita, K. Lee, and P. S. Tsao, "Cyclic Strain induces reactive oxygen species production via an endothelial $\mathrm{NAD}(\mathrm{P}) \mathrm{H}$ oxidase," J. Cell Biochem., vol. 81, pp. 99-106, 2001.

[38] L.-F. Li, B. Ouyang, G. Choukroun, R. Matyal, M. Mascarenhas, B. Jafari, J. V. Bonventre, T. Force, and D. A. Quinn, "Stretchinduced IL-8 depends on c-Jun NH2-terminal and nuclear factor-Binducing kinases," Am. J. Physiol. Lung Cell Mol. Physiol., vol. 285, pp. L464-L475, 2003.
[39] K. Sudhir, E. Wilson, K. Chatterjee, and H. E. Ives, "Mechanical strain and collagen potentiate mitogenic activity of angiotensin II in rat vascular smooth muscle cells," J. Clin. Invest., vol. 92, pp. 3003-7, Dec 1993.

[40] E. Wilson, F. Vives, T. Collins, and H. E. Ives, "Strain-responsive regions in the platelet-derived growth factor-A gene promoter," Hypertension, vol. 31, pp. 170-5, Jan 1998.

[41] K. Okada, S. Ishikawa, and T. Saito, "Interaction between endothelin-induced $\mathrm{Na}+$ and $\mathrm{Ca} 2+$ kinetics in cultured rat vascular smooth muscle cells," J. Cardiovasc. Pharmacol., vol. 17(Suppl 7), pp. S124-6, 1991.

[42] A. Sachinidis, R. Locher, W. Vetter, D. Tatje, and J. Hoppe, "Different effects of platelet-derived growth factor isoforms on rat vascular smooth muscle cells," J. Biol. Chem., vol. 265, pp. 1023843, Jun 251990.

[43] W. C. Lee, T. M. Maul, D. A. Vorp, J. P. Rubin, and K. G. Marra, "Effects of uniaxial cyclic strain on adipose-derived stem cell morphology, proliferation, and differentiation," Biomech. Model. Mechanobiol., vol. 6, pp. 265-73, July 2007.

[44] S. Ling, G. Deng, H. E. Ives, K. Chatterjee, G. M. Rubanyi, P. A. Komesaroff, and K. Sudhir, "Estrogen inhibits mechanical straininduced mitogenesis in human vascular smooth muscle cells via down-regulation of Sp-1," Cardiovasc. Res., vol. 50, pp. 108-14, Apr 2001.

[45] M. A. Hill, H. Zou, S. J. Potocnik, G. A. Meininger, and M. J. Davis, "Invited review: arteriolar smooth muscle mechanotransduction: $\mathrm{Ca}(2+)$ signaling pathways underlying myogenic reactivity," J. Appl. Physiol., vol. 91, pp. 973-83, Aug 2001 .

[46] R. D. Rosenberg, "Vascular smooth muscle cell proliferation: basic investigations and new therapeutic approaches," Thromb. Haemost., vol. 70, pp. 10-6, July 1993.

[47] C. Li, and Q. Xu, "Mechanical stress-initiated signal transductions in vascular smooth muscle cells," Cell Signal., vol. 12, pp. 435-45, Jul 2000.

[48] G. Osol, "Mechanotransduction by vascular smooth muscle," $J$. Vasc. Res., vol. 32, pp. 275-92, Sep-Oct 1995.

[49] A. C. Newby, and A. B. Zaltsman, "Molecular mechanisms in intimal hyperplasia," J. Pathol., vol. 190, pp. 300-9, Feb 2000.

[50] M. Papadaki, S. G. Eskin, J. Ruef, M. S. Runge, and L. V. McIntire, "Fluid shear stress as a regulator of gene expression in vascular cells: possible correlations with diabetic abnormalities," Diabetes Res. Clin. Pract., vol. 45, pp. 89-99, Sep 1999.

[51] B. P. Nolan, P. Senechal, S. Waqar, J. Myers, C. A. Standley, and P. R. Standley, "Altered insulin-like growth factor-1 and nitric oxide sensitivities in hypertension contribute to vascular hyperplasia," Am. J. Hypertens, vol. 16, pp. 393-400, May 2003.

[52] W. Rafflenbeul, "Hypertension treatment and prevention of new atherosclerotic plaque formation," Drugs, vol. 48(Suppl 1), pp. 11$5,1994$.

[53] B. J. Basha, and J. R. Sowers, "Atherosclerosis: an update," Am. Heart J., vol. 131, pp. 1192-202, Jun 1996.

[54] P. D. Bonin, G. J. Fici, and J. P. Singh, "Interleukin-1 promotes proliferation of vascular smooth muscle cells in coordination with PDGF or a monocyte derived growth factor," Exp. Cell Res., vol. 181, pp. 475-82, Apr 1989.

[55] U. Ikeda, M. Ikeda, T. Oohara, S. Kano, and T. Yaginuma, "Mitogenic action of interleukin-1 alpha on vascular smooth muscle cells mediated by PDGF," Atherosclerosis, vol. 84, pp. 1838, Oct 1990.

[56] X. Z. Ruan, J. F. Moorhead, J. L. Tao, K. L. Ma, D. C. Wheeler, S. H. Powis, and Z. Varghese, "Mechanisms of dysregulation of lowdensity lipoprotein receptor expression in vascular smooth muscle cells by inflammatory cytokines," Arterioscler. Thromb. Vasc. Biol., vol. 26, pp. 1150-5, May 2006.

[57] S. Morimoto, T. Nabata, E. Koh, T. Shiraishi, K. Fukuo, S. Imanaka, S. Kitano, Y. Miyashita, and T. Ogihara, "Interleukin-6 stimulates proliferation of cultured vascular smooth muscle cells independently of interleukin-1 beta," J. Cardiovasc. Pharmacol., vol. 17, pp. S117-8, 1991.

[58] E. Alpert, A. Gruzman, B. Lardi-Studler, G. Cohen, R. Reich, and S. Sasson, "Cyclooxygenase-2 (PTGS2) inhibitors augment the rate of hexose transport in L6 myotubes in an insulin- and AMPKalphaindependent manner," Diabetologia, vol. 49, pp. 562-70, Mar 2006. 
[59] B. J. Ballermann, A. Dardik, E. Eng, and A. Liu, "Shear stress and the endothelium," Kidney Int. Suppl., vol. 67, pp. S100-8, Sep 1998.

[60] S. Kato, A. Muraishi, T. Miyamoto, and J. C. Fox, "Basic fibroblast growth factor regulates extracellular matrix and contractile protein expression independent of proliferation in vascular smooth muscle cells," In Vitro Cell Dev. Biol. Anim., vol. 34, pp. 341-6, Apr 1998.

[61] L. Bai, Z. Yu, G. Qian, P. Qian, J. Jiang, G. Wang, and C. Bai, "SOCS3 was induced by hypoxia and suppressed STAT3 phosphorylation in pulmonary arterial smooth muscle cells," Respir. Physiol. Neurobiol., vol. 152, pp. 83-91, May 2006.

[62] M. Fernandez, M. F. Segura, C. Sole, A. Colino, J. X. Comella, and V. Cena, "Lifeguard/neuronal membrane protein 35 regulates Fas ligand-mediated apoptosis in neurons via microdomain recruitment," J. Neurochem., vol. 103, pp. 190-203, Oct 2007.

[63] P. Kannan-Thulasiraman, and D. J. Shapiro, "Modulators of inflammation use nuclear factor-kappa B and activator protein-1 sites to induce the caspase-1 and granzyme B inhibitor, proteinase inhibitor 9," J. Biol. Chem., vol. 277, pp. 41230-9, Oct 252002.

[64] K. B. Lemstrom, A. I. Nykanen, J. M. Tikkanen, R. Krebs, R. K. Sihvola, E. A. Kallio, R. Olivier, and P. K. Koskinen, "Role of angiogenic growth factors in transplant coronary artery disease," Ann. Med., vol. 36, pp. 184-93, 2004

[65] K. Rakesh, and D. K. Agrawal, "Cytokines and growth factors involved in apoptosis and proliferation of vascular smooth muscle cells," Int. Immunopharmacol., vol. 5, pp. 1487-506, Sep 2005.

[66] Y. Feng, J. H. Yang, H. Huang, S. P. Kennedy, T. G. Turi, J. F. Thompson, P. Libby, and R. T. Lee, "Transcriptional profile of mechanically induced genes in human vascular smooth muscle cells," Circ. Res., vol. 85, pp. 1118-23, Dec 3-17 1999.

[67] H. Zhang, S. W. Cowan-Jacob, M. Simonen, W. Greenhalf, J. Heim, and B. Meyhack, "Structural basis of BFL-1 for its interaction with BAX and its anti-apoptotic action in mammalian and yeast cells," J. Biol. Chem., vol. 275, pp. 11092-9, Apr 14 2000.

[68] K. Schultz, V. Murthy, J. B. Tatro, and D. Beasley, "Endogenous interleukin-1 alpha promotes a proliferative and proinflammatory phenotype in human vascular smooth muscle cells," Am. J. Physiol. Heart Circ. Physiol., vol. 292, pp. H2927-34, June 2007.

[69] A. Kumar, A. J. Knox, and A. M. Boriek, "CCAAT/enhancerbinding protein and activator protein-1 transcription factors regulate the expression of interleukin- 8 through the mitogenactivated protein kinase pathways in response to mechanical stretch of human airway smooth muscle cells," J. Biol. Chem., vol. 278, pp. 18868-76, May 232003.

[70] A. D. Johnson, P. A. Berberian, M. Tytell, and M. G. Bond, "Differential distribution of $70-\mathrm{kD}$ heat shock protein in atherosclerosis. Its potential role in arterial SMC survival," Arterioscler. Thromb. Vasc. Biol., vol. 15, pp. 27-36, Jan 1995.

[71] Q. Xu, G. Schett, C. Li, Y. Hu, and G. Wick, "Mechanical stressinduced heat shock protein 70 expression in vascular smooth muscle cells is regulated by Rac and Ras small G proteins but not mitogen-activated protein kinases," Circ. Res., vol. 86, pp. 1122-8, June 92000

[72] H. Zhang, and S. N. Cohen, "Smurf2 up-regulation activates telomere-dependent senescence," Genes. Dev., vol. 18, pp. 302840, Dec 152004

[73] J. D. Kakisis, S. Pradhan, A. Cordova, C. D. Liapis, and B. E. Sumpio, "The role of STAT-3 in the mediation of smooth muscle cell response to cyclic strain," Int. J. Biochem. Cell Biol., vol. 37, pp. 1396-406, Jul 2005.

[74] Q. Chen, W. Li, Z. Quan, and B. E. Sumpio, "Modulation of vascular smooth muscle cell alignment by cyclic strain is dependent on reactive oxygen species and P38 mitogen-activated protein kinase," J. Vasc. Surg., vol. 37, pp. 660-8, Mar 2003.

[75] A. Dardik, A. Yamashita, F. Aziz, H. Asada, and B. E. Sumpio, "Shear stress-stimulated endothelial cells induce smooth muscle cell chemotaxis via platelet-derived growth factor-BB and interleukin-1alpha," J. Vasc. Surg., vol. 41, pp. 321-31, Feb 2005.

[76] B. Liu, M. J. Qu, K. R. Qin, H. Li, Z. K. Li, B. R. Shen, and Z. L. Jiang, "Role of cyclic strain frequency in regulating the alignment of vascular smooth muscle cells in vitro," Biophys. J., vol. 94, pp. 1497-507, Feb 152008

Received: May 21, 2009

Revised: July 06, 2009

Accepted: July 09, 2009

(C) Kona et al.; Licensee Bentham Open.

This is an open access article licensed under the terms of the Creative Commons Attribution Non-Commercial License (http://creativecommons.org/licenses/by-nc/3.0/) which permits unrestricted, non-commercial use, distribution and reproduction in any medium, provided the work is properly cited. 